\title{
Urinary tuberculosis is associated with the development of urothelial carcinoma but not renal cell carcinoma: a nationwide cohort study in Taiwan
}

\begin{abstract}
Y-C Lien ${ }^{1}$, J-Y Wang ${ }^{2}$, M-C Lee ${ }^{3}$, C-C Shu ${ }^{4}, \mathrm{H}-\mathrm{Y}$ Chen $^{1}$, C-H Hsieh ${ }^{5,6}, \mathrm{C}-\mathrm{H}$ Lee $^{\star, 1,6}$, L-N Lee ${ }^{7}$ and K-M Chao ${ }^{8}$
${ }^{1}$ Department of Internal Medicine, Taipei Tzu Chi Hospital, Buddhist Tzu Chi Medical Foundation, Taipei Branch, No. 289, Jianguo Road, Xindian District, New Taipei City 23142, Taiwan; ${ }^{2}$ Department of Internal Medicine, National Taiwan University Hospital, No. 7, Chung-Shan South Road, Taipei 10002, Taiwan; ${ }^{3}$ Department of Pharmacy, Taipei Tzu Chi Hospital, Buddhist Tzu Chi Medical Foundation, Taipei Branch, No. 289, Jianguo Road, Xindian District, New Taipei City 23142, Taiwan; ${ }^{4}$ Department of Traumatology, National Taiwan University Hospital, No. 7, Chung-Shan South Road, Taipei 10002, Taiwan; ${ }^{5}$ Division of Urology, Department of Surgery, Taipei Tzu Chi Hospital, Buddhist Tzu Chi Medical Foundation, Taipei Branch, No. 289, Jianguo Road, Xindian District, New Taipei City 23142, Taiwan; 'SChool of Medicine, Tzu Chi University, No.701, Zhongyang Road, Sec. 3, Hualien 97004, Taiwan; ${ }^{7}$ Department of Laboratory Medicine, National Taiwan University Hospital, No. 7, Chung-Shan South Road, Taipei 10002, Taiwan and ${ }^{8}$ Graduate Institute of Biomedical Electronics and Bioinformatics, National Taiwan University, No. 1, Roosevelt Road, Sec. 4, Taipei 10617, Taiwan
\end{abstract}

Background: Obstructive uropathy and chronic urinary tract infection increase the risk of urinary tract cancer. Urinary tuberculosis (UTB) can cause chronic urinary tract inflammation, lead to obstructive uropathy, and potentially contribute to the development of urinary tract cancer. However, the association between UTB and urinary tract cancer has not been studied.

Methods: This study enrolled 135142 tuberculosis (TB) cases (male, 69\%) from a nationwide health insurance research database in Taiwan and investigated the risk factors for urinary tract cancer, with emphasis on a history of UTB. The incidence of urinary tract cancer in the general population without TB was also calculated for comparison.

Results: The TB patients had a mean age of $57.5 \pm 19.5$ years. Of the 1287 UTB and 133855 non-UTB patients, $15(1.2 \%)$ and $396(0.3 \%)$ developed urothelial carcinoma, respectively $(P<0.001)$; and $2(0.2 \%)$ and $96(0.1 \%)$ developed renal cell carcinoma, respectively $(P=0.240)$. Cox regression analysis revealed that age, male sex, end-stage renal disease, obstructive uropathy, arsenic intoxication, organ transplantation, and UTB (hazard ratio: 3.38 (2.01-5.69)) were independent risk factors for urothelial carcinoma. The hazard ratio of UTB was higher among female patients (5.26 (2.12-13.06)) than that among male patients $(2.96$ (1.57-5.60)).

Conclusion: Urinary tuberculosis had a strong association with urothelial carcinoma, but not with renal cell carcinoma. In TB endemic areas, the urinary tract of TB patients should be scrutinised. It is also imperative that these patients be followed-up carefully in the post-treatment period, and urinalysis, ultrasonography or endoscopy should be an integral part of the follow-up.

Urinary tract cancer, including urothelial carcinoma and renal cell carcinoma, are major malignant diseases worldwide. Bladder cancer is the principal malignancy of the urinary tract and the ninth most common malignancy worldwide (Ploeg et al, 2009).

${ }^{\star}$ Correspondence: Dr C-H Lee; E-mail: chlee.tw@gmail.com

Received 15 May 2013; revised 23 July 2013; accepted 14 August 2013;

published online 15 October 2013

(c) 2013 Cancer Research UK. All rights reserved 0007-0920/13

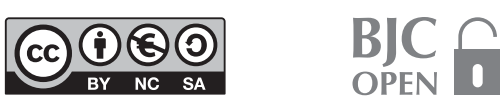


Urothelial carcinoma is typically diagnosed in elderly individuals, with a median age of 69-71 years (Lynch and Cohen, 1995; Scosyrev et al, 2009), and is associated with male sex and exogenous and environmental risk factors such as chemical carcinogens, cigarette smoking, arsenic, medications (i.e., Phenacetin, Cyclophosphamide and hiazolidinediones), aristolochic acid, and chronic infection/inflammation (Johansson and Cohen, 1997; De Ridder et al, 1998; Pommer et al, 1999; Kakehi et al, 2010; Lai et al, 2010b; Mamtani et al, 2012). In addition, cigarette smoking, hypertension, analgesics and obesity are associated with a higher risk of developing renal cell carcinoma (Chow et al, 2000; Ljungberg et al, 2011). In Taiwan, the incidence of urinary tract cancer in 2009 was 23.1 and 14.5 per 100000 person-year for men and women, respectively (Bureau of Health Promotion, Deparment of Health, 2009).

Tuberculosis (TB), a global public health threat, is still a leading cause of death, especially in underdeveloped and developing countries (Blanc et al, 2010). Although its incidence and mortality rates have steadily declined since 1950, TB remains a leading infectious disease in Taiwan (Chang et al, 2010b; Dou et al, 2011). It is characterised by chronic caseous granulomatous inflammation that can occur in any organ to cause tissue destruction and structural distortion (Elkington et al, 2011). Urinary TB (UTB) is a relatively common form of extra-pulmonary TB, constituting 3-5\% of all TB cases (Wise and Marella, 2003). If not detected or treated early, it may cause urinary tract scaring and later, obstructive uropathy and urinary tract infection or inflammation (Ardalan and Shoja, 2008). In chronic inflammation, the urinary tract mucosa is predisposed to cell dysplasia and urinary tract cancer (Ling et al, 2011). However, the association between UTB and urinary tract cancer, including urothelial carcinoma and renal cell carcinoma, has never been investigated.

Using the National Health Insurance Research Database (NHIRD) of Taiwan, the present study analysed a nationwide cohort with a follow-up duration of 15 years to investigate the risk factors for urinary tract cancer, with an emphasis on prior UTB history.

\section{METHODS}

The Institutional Review Board of Buddhist Tzu Chi General Hospital, Taipei Branch, Taiwan, approved the study and waived informed consent owing to the retrospective design. Patients with TB were identified from the NHIRD. The influence of UTB and other co-morbidities on the risk of developing urinary tract cancer were studied. All selected cases were followed-up until 31 December 2010 or until the patients were either lost to follow-up (cancelled health insurance prior to 31 December 2010) or developed urinary tract cancer.

Selection criteria for active TB. Active TB was defined by at least two ambulatory visits or one in-patient record with a compatible diagnosis (ICD-9-CM codes $010-018$ and A-codes A020-A022, A025), prescriptions consisting of at least two anti-TB drugs simultaneously for $\geqslant 120$ days of a 180 -day period, and at least one prescription consisting of three or more anti-TB drugs. The anti-TB drugs included isoniazid, rifampicin, ethambutol, pyrazinamide, prothionamide, terizidone, streptomycin, kanamycin, quinolones, cycloserine, and aminosalicylic acid. The individual anti-TB agents were converted from the claims data according to the defined daily doses and grouped according to their pharmacologic categories (WHO International Working Group for Drug Statistics Methodology, 2011; Lee et al, 2013). For patients with end-stage renal disease (ESRD), the prescriptions were adjusted accordingly (Luh, 2011).

The index date was defined as the initial date of anti-TB treatment, which was moved forward if there were other respiratory diagnoses or orders of acid-fast smear, mycobacterial culture, bronchoscopy, pleural biopsy, or tuberculin skin test within 180 days prior to start of anti-TB treatment, as previously reported (Lee et al, 2012). Patients with TB and an index date between 1 January 1998 and 31 December 2008 were enrolled. Those with follow-up duration $<1$ year prior to the index date were excluded to ensure a sufficient observation period for identifying co-morbidities and preexisting history of urinary tract cancer. Patients who develop urinary tract cancer within 1 year after the index date were also excluded. Urinary TB was identified by specific diagnoses (ICD-9-CM 016, 016.0-016.3, 016.9, and A-code A025).

Identifying patients with urinary tract cancer. The urinary tract cancer was identified by compatible ICD-9-CM codes (188 and 189 ) or A-codes (A126 and A129) from the Registry for Catastrophic Illness Patient Database, a separate section of the NHIRD that required histologic confirmation. Patients with urinary tract cancer were further classified as having renal cell carcinoma (ICD-9-CM 189 and 189.0) or urothelial carcinoma (all other else among ICD-9-CM 188 and 189). The selection process and the incidence rates of urinary tract cancer among TB patients are shown in Figure 1.

The incidence of urinary tract cancer during the study period was also calculated in the non-TB general population from the Longitudinal Health Insurance Database 2010 (LHID 2010), a subset of the NHIRD containing the original claims data of one million beneficiaries enrolled in 2010 randomly sampled from the registry for beneficiaries. The characteristics of the LHID have been described previously (Lee et al, 2012).

Co-morbidities and other diseases. Malignancy other than urinary tract cancer, chronic obstructive pulmonary disease (COPD), ESRD, liver cirrhosis, organ transplantation, autoimmune diseases, and acquired immuno-deficiency disease were identified according to a previous publication (Lee et al, 2012). Patients were considered as having diabetes mellitus if they had at least one hospital admission or three (or more) out-patient visits with a compatible diagnostic code (ICD-9-CM code 250 or A-code A181) within 365 calendar days. To avoid including women with gestational diabetes, diabetes visit claims within 270 days before parturition were excluded (Chang et al, 2010a). Urinary tract infections were identified by diagnostic codes (ICD-9-CM codes 590, 595, 597, and 599.0 and A-codes A351, A353, and A359) within 1 month prior to or after the index date. Obstructive uropathy was identified by compatible diagnostic codes (ICD-9-CM codes 591, 592, 594, 596, 598, 599.3, and 599.6, and A-codes A352 and A359) prior to the index date. Arsenic intoxication was identified by any ambulatory visit or in-patient records with the diagnosis code ICD9-CM 985.1. The low income group was identified from the insurance status, and was defined as having an annual household income below 4500 US dollars (Public Assistance Act, 2010).

Statistical analysis. Inter-group differences were compared using the independent sample $t$-test or analysis of variance for numerical variables and the $\chi^{2}$-square test, Fisher's exact test for categorical variables, or generalised estimating equations for incidence rates as appropriate. Curves of time to urothelial carcinoma and renal cell carcinoma were generated using the Kaplan-Meier method and compared using the log rank test.

The effects of UTB and other co-morbidities on the risk of developing urothelial carcinoma and renal cell carcinoma were investigated separately using the Cox proportional hazards model. Variables included sex, age, co-morbidities, and adherence to antiTB treatment. Because tobacco use was uncommon in female Taiwanese (4\%) (Wen et al, 2005), analysis was restricted to subpopulations of female and male patients separately to explore the confounding effects of smoking. To explore the possible interaction of UTB with different age groups, sub-population analyses were 


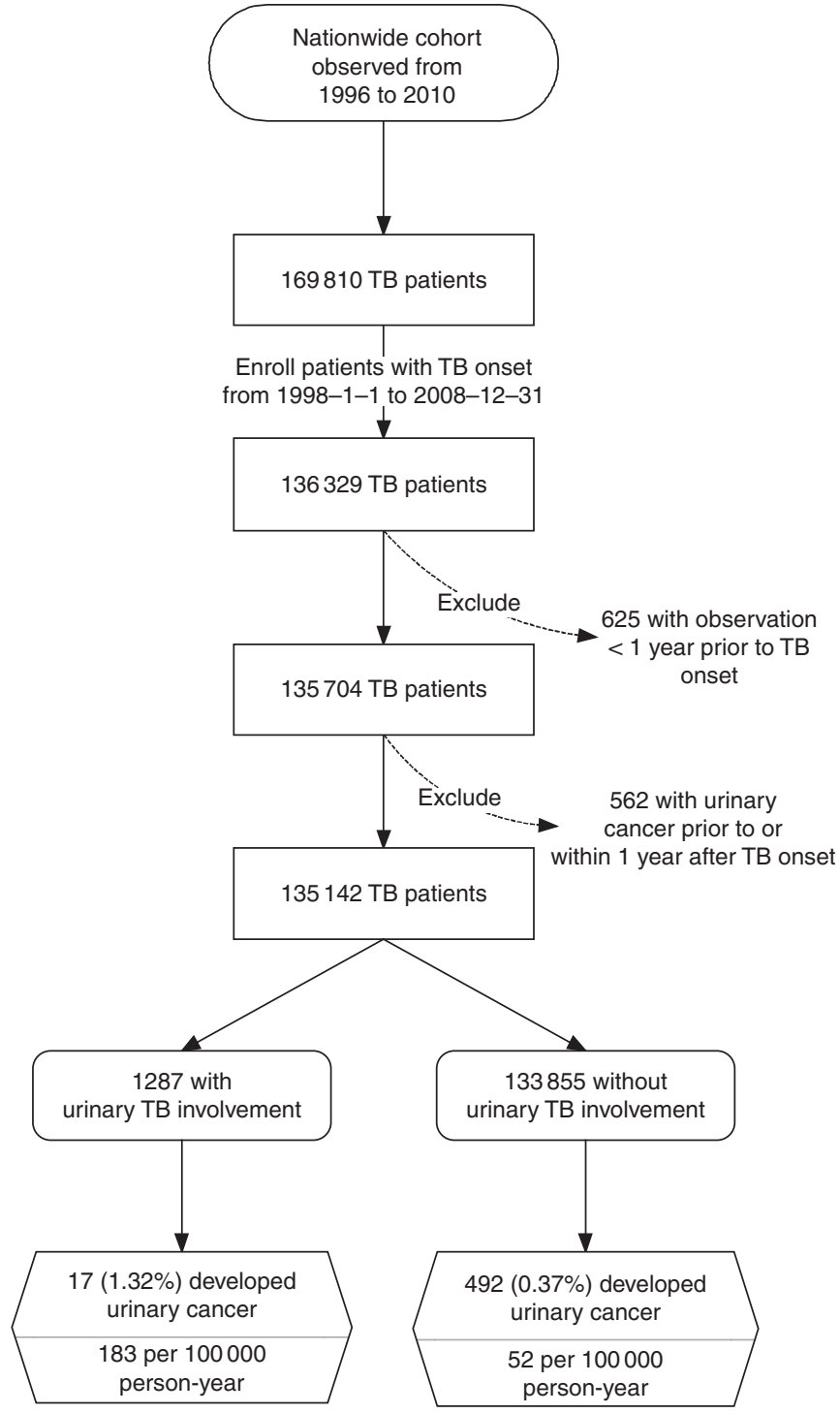

Figure 1. The selection process of identifying TB cases with and without UTB from a nationwide cohort, and the corresponding incidence of urinary tract cancer.

also performed by dividing the TB patients into those $<60$ or $\geqslant 60$ years of age.

Basic model-fitting techniques, including variable selection, goodness-of-fit, adjusted generalised $R^{2}$, and regression diagnostics (residual analysis, detection of influential cases, and check for multi-collinearity) were applied to ensure the quality of the multivariate analysis. Significance levels for entry and stay were set at 0.15 . Statistical significance was set at a two-sided $P<0.05$. All analyses were performed using the SAS software (SAS Institute Inc., Cary, NC, USA).

\section{RESULTS}

From a nationwide cohort of $>27$ million beneficiaries, 169810 TB cases were identified, including 136369 with TB onset during the study period (Figure 1). Among them, 625 with $<1$ year observation duration prior to $\mathrm{TB}$ onset and 562 patients who developed urinary tract cancer within 1 year after TB onset were excluded. The remaining 135142 TB patients (956936 personyears) were included for further analysis.
Table 1. Clinical characteristics of tuberculosis patients with and without urinary involvement $(n=135142)$

\begin{tabular}{|c|c|c|c|}
\hline & Yes & No & \\
\hline $\begin{array}{l}\text { Urinary involvement of } \\
\text { tuberculosis }\end{array}$ & $n=1287$ & $n=133855$ & $P$-value \\
\hline Age (year) & $58.9 \pm 16.7$ & $57.1 \pm 19.6$ & $<0.001^{a}$ \\
\hline Male & $820(63.7 \%)$ & 92069 (68.8\%) & $<0.001^{b}$ \\
\hline $\begin{array}{l}\text { Developing urinary tract } \\
\text { cancer }\end{array}$ & $17(1.3 \%)$ & $492(0.4 \%)$ & $<0.001^{b}$ \\
\hline $\begin{array}{l}\text { Renal cell carcinoma } \\
\text { Urothelial carcinoma }\end{array}$ & $\begin{array}{r}2(0.2 \%) \\
15(1.2 \%)\end{array}$ & $\begin{array}{r}96(0.1 \%) \\
396(0.3 \%)\end{array}$ & $\begin{array}{r}0.240^{\mathrm{c}} \\
<0.001^{\mathrm{b}}\end{array}$ \\
\hline Follow-up duration (year) & $7.2 \pm 3.3$ & $7.1 \pm 3.2$ & $0.182^{a}$ \\
\hline Cancelled health insurance & $45(3.5 \%)$ & $5368(4.0 \%)$ & $0.350^{b}$ \\
\hline Diabetes mellitus & $275(21.4 \%)$ & 30209 (22.6\%) & $0.305^{b}$ \\
\hline Obstructive uropathy & $571(44.4 \%)$ & 18499 (13.8\%) & $<0.001^{b}$ \\
\hline Urinary tract infection & $582(45.2 \%)$ & $8187(6.1 \%)$ & $<0.001^{b}$ \\
\hline COPD & 125 (9.7\%) & $19111(14.3)$ & $<0.001^{b}$ \\
\hline Malignancy & $28(2.2 \%)$ & $4643(3.5 \%)$ & $0.011^{b}$ \\
\hline ESRD & $32(2.5 \%)$ & $1527(1.1 \%)$ & $<0.001^{b}$ \\
\hline Autoimmune disease & $16(1.2 \%)$ & $971(0.7 \%)$ & $0.030^{b}$ \\
\hline Liver cirrhosis & $5(0.4 \%)$ & $269(0.2 \%)$ & $0.195^{c}$ \\
\hline Transplantation & $7(0.5 \%)$ & $118(0.1 \%)$ & $<0.001^{c}$ \\
\hline $\begin{array}{l}\text { Acquired immuno-deficiency } \\
\text { syndrome }\end{array}$ & $3(0.2 \%)$ & $192(0.1 \%)$ & $0.439^{c}$ \\
\hline Arsenic intoxication & $1(0.1 \%)$ & $26(0.0 \%)$ & $0.228^{c}$ \\
\hline Low-income status & $27(2.1 \%)$ & 3954 (3.0\%) & $0.071^{b}$ \\
\hline
\end{tabular}

No. of days in first 2 months of anti-tuberculosis treatment

\begin{tabular}{|l|c|c|c|}
\hline $\begin{array}{l}\text { Receiving no } \\
\text { anti-tuberculosis agents }\end{array}$ & $4.5 \pm 7.8$ & $3.5 \pm 7.0$ & $<0.001^{\mathrm{a}}$ \\
$\begin{array}{l}\text { Receiving } \geqslant 3 \\
\text { anti-tuberculosis agents }\end{array}$ & $45.1 \pm 14.5$ & $48.6 \pm 12.6$ & $<0.001^{\mathrm{a}}$ \\
\hline $\begin{array}{l}\text { Complete treatment with } \\
\text { standard anti-tuberculosis } \\
\text { regimen }\end{array}$ & $879(68.3 \%)$ & $96209(71.9 \%)$ & $0.005^{\mathrm{b}}$ \\
\hline
\end{tabular}

Abbreviations: $C O P D=$ chronic obstructive pulmonary disease; $E S R D=$ end-stage renal disease.

${ }^{\text {a }}$ Calculated by independent-sample Student's t-test.

${ }^{\text {b }}$ Calculated by $\chi^{2}$-square test.

${ }^{\mathrm{c} C a l c u l a t e d}$ by Fisher's exact test.

Data were either number (\%) or mean \pm s.d.

The mean age of the TB cases was $57.5 \pm 19.5$ years, with a male-female ratio of 2.2. The mean and median durations of follow-up were $7.1 \pm 3.2$ and 7.0 years, respectively. Male TB patients (mean age, 59.2 \pm 18.5 years) were older than female patients (mean age, $52.5 \pm 21.0$ years). Urinary TB was diagnosed in $1287(1.0 \%)$ (Table 1). Forty-five $(3.5 \%)$ of the patients with UTB and $5368(4.0 \%)$ of those without UTB cancelled health insurance $\left(P=0.350\right.$ by the $\chi^{2}$-square test).

The most common underlying co-morbidities among UTB patients were obstructive uropathy, diabetes mellitus, COPD, and ESRD. Compared with patients without UTB, UTB patients were more likely to have obstructive uropathy, urinary tract infection, autoimmune disease, ESRD, and previous history of organ transplantation. Of the TB cases, $64.5 \%$ strictly adhered to and completed the standard four-combined regimen TB treatment (i.e., isoniazid, rifampicin, ethambutol, and pyrazinamide in the first 2 months, followed by isoniazid, rifampicin with or without 
Table 2. Incidence of urinary tract cancer (per 100000 person-year) in patients with TB and in the general population without TB

\begin{tabular}{|c|c|c|c|c|c|c|}
\hline \multirow[b]{2}{*}{ Age } & \multicolumn{3}{|c|}{ Male } & \multicolumn{3}{|c|}{ Female } \\
\hline & TB & non-TB & $P$-value ${ }^{a}$ & TB & non-TB & $P$-value ${ }^{a}$ \\
\hline$<40$ years & 1.0 & 1.4 & 0.807 & 4.6 & 0.8 & 0.001 \\
\hline $\begin{array}{l}\text { Renal cell carcinoma } \\
\text { Urothelial carcinoma }\end{array}$ & $\begin{array}{c}1.0 \\
0\end{array}$ & $\begin{array}{l}0.7 \\
0.7\end{array}$ & 0.678 & $\begin{array}{l}1.1 \\
3.4\end{array}$ & $\begin{array}{l}0.5 \\
0.3\end{array}$ & $\begin{array}{r}0.452 \\
<0.001\end{array}$ \\
\hline $40-60$ years & 26.8 & 19.1 & 0.026 & 14.7 & 7.9 & 0.105 \\
\hline $\begin{array}{l}\text { Renal cell carcinoma } \\
\text { Urothelial carcinoma }\end{array}$ & $\begin{array}{l}10.6 \\
16.2\end{array}$ & $\begin{array}{c}7.6 \\
11.5\end{array}$ & $\begin{array}{l}0.126 \\
0.104\end{array}$ & $\begin{array}{c}1.1 \\
13.6\end{array}$ & $\begin{array}{l}2.9 \\
5.0\end{array}$ & $\begin{array}{l}0.396 \\
0.002\end{array}$ \\
\hline$\geqslant 60$ years & 94.1 & 99.6 & 0.446 & 63.9 & 54.4 & 0.138 \\
\hline $\begin{array}{l}\text { Renal cell carcinoma } \\
\text { Urothelial carcinoma }\end{array}$ & $\begin{array}{l}15.9 \\
78.2\end{array}$ & $\begin{array}{l}19.0 \\
80.6\end{array}$ & $\begin{array}{l}0.296 \\
0.721\end{array}$ & $\begin{array}{l}12.1 \\
51.8\end{array}$ & $\begin{array}{l}18.7 \\
35.7\end{array}$ & $\begin{array}{l}0.143 \\
0.014\end{array}$ \\
\hline
\end{tabular}

ethambutol for the next 4 months). Another $7.4 \%$ received the standard triple chemotherapy of isoniazid, rifampicin plus ethambutol. Relapse of TB occurred in 4721 (3.5\%) of the enrolled TB patients.

Urothelial carcinoma and renal cell carcinoma were diagnosed in $411(0.4 \%)$ and $98(0.1 \%)$ of the TB patients, corresponding to incidence rates of 43 and 10 per 100000 person-years, respectively. In both the $\mathrm{TB}$ patients and the non-TB general population, the incidence of urinary tract cancer (either renal cell carcinoma or urothelial carcinoma) increased with age (Table 2). Among those aged 40-60 years, TB patients had a higher risk of developing urinary tract cancer than the non-TB population. Except for patients younger than 40 years, male patients had a higher incidence of urinary tract cancer than female patients. For female patients, the incidence of urothelial carcinoma was remarkably higher among the TB patients than among the non-TB general population across all age groups, and especially in the younger subjects. There were no differences in the incidence of renal cell carcinoma between the TB and non-TB subjects in both male and female patients.

The mean interval between the index date of TB and the diagnosis of urinary tract cancer was $4.7 \pm 2.8$ years. The most common site of urinary tract cancer involvement was the bladder (69\%), followed by the kidneys (19\%), renal pelvis (6\%), ureter (6\%), and urethra (1\%). Patients with UTB were older and had significantly higher risk of developing urothelial carcinoma than those without UTB $\left(1.3 \%\right.$ vs $0.4 \%, P<0.001$, by $\chi^{2}$-square test $)$ (Table 1). The curves of time to development of urothelial carcinoma in patients with and without UTB were significantly different by the log rank test (Figure 2). The curves of time to the development of renal cell carcinoma overlapped for the patients with and without UTB (Figure 3).

Among all TB patients enrolled, the clinical characteristics for those who developed urothelial carcinoma, renal cell carcinoma and those without subsequent urinary malignancy are summarised in Table 3. The mean interval from the index date of TB to the diagnosis of urothelial carcinoma and renal cell carcinoma were $4.6 \pm 2.7$ and $5.1 \pm 3.1$ years, respectively.

Cox proportional hazards model analysis of all the variables listed in Table 1 for the 135142 TB cases revealed that UTB was an independent risk factor for urothelial carcinoma (hazard ratio 3.38 (95\% confidence interval, 2.01-5.69)) (Table 4). Moreover, age, male sex, ESRD, obstructive uropathy, organ transplantation and arsenic intoxication significantly increased the risk of developing urothelial carcinoma. Age, male sex, ESRD and obstructive

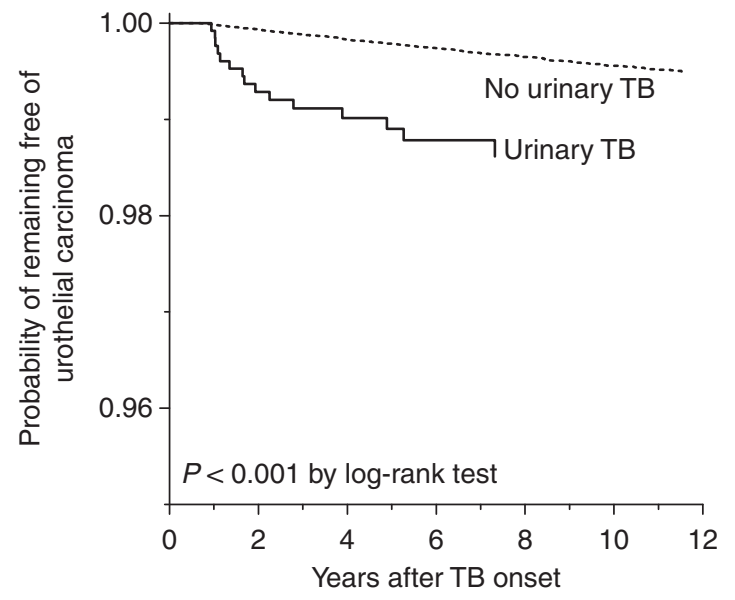

Figure 2. The curves of time to the development of urothelial carcinoma generated by the Kaplan-Meier method among TB patients with and without UTB.

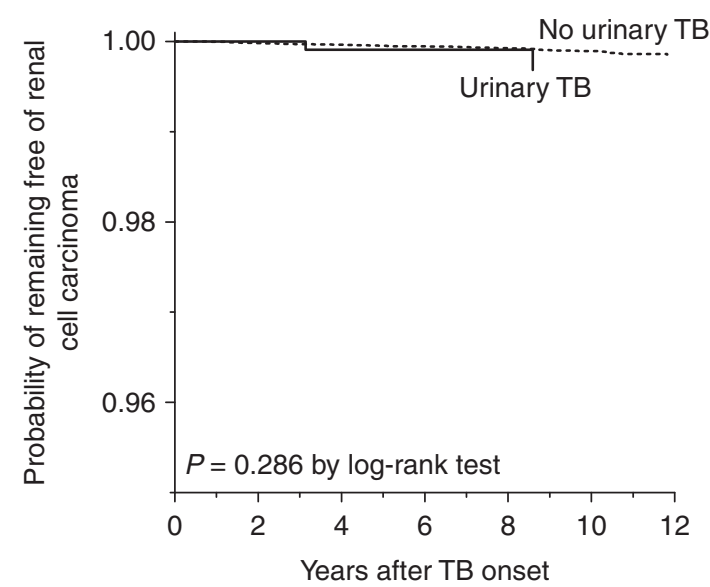

Figure 3. The curves of time to the development of renal cell carcinoma generated by the Kaplan-Meier method among the TB patients with and without UTB.

uropathy were independent risk factors for developing renal cell carcinoma. However, UTB was not associated with the development of renal cell carcinoma (Table 5). In sub-population analysis 
Table 3. Clinical characteristics of tuberculosis patients with and without urinary tract cancer $(n=135142)$

\begin{tabular}{|c|c|c|c|c|}
\hline Developing urinary tract cancer & Urothelial carcinoma $n=411$ & Renal cell carcinoma $n=98$ & No $n=134633$ & $\boldsymbol{P}$-value \\
\hline Age (year) & $69.8 \pm 10.6$ & $64.7 \pm 12.6$ & $57.1 \pm 19.6$ & $<0.001^{a}$ \\
\hline Male & $327(79.6 \%)$ & $81(82.7 \%)$ & $92481(68.7 \%)$ & $<0.001^{b}$ \\
\hline Urinary tuberculosis & $15(3.6 \%)$ & $2(2.0 \%)$ & $1270(0.9 \%)$ & $<0.001^{b}$ \\
\hline Follow-up duration (year) & $4.6 \pm 2.7$ & $5.1 \pm 3.1$ & $7.1 \pm 3.2$ & $<0.001^{a}$ \\
\hline Diabetes mellitus & $116(28.2 \%)$ & $29(29.6 \%)$ & 30339 (22.5\%) & $0.006^{b}$ \\
\hline Obstructive uropathy & $92(22.4 \%)$ & $23(23.5 \%)$ & 18955 (14.1\%) & $<0.001^{b}$ \\
\hline Urinary tract infection & $41(10.0 \%)$ & $9(9.2 \%)$ & 8719 (6.5\%) & $0.002^{b}$ \\
\hline COPD & $83(20.2 \%)$ & $15(15.3 \%)$ & $19138(14.2 \%)$ & $0.002^{b}$ \\
\hline Malignancy & $17(4.1 \%)$ & $4(4.1 \%)$ & $4650(3.5 \%)$ & $0.709^{b}$ \\
\hline End-stage renal disease & $29(7.1 \%)$ & $6(6.1 \%)$ & $1524(1.1 \%)$ & $<0.001^{b}$ \\
\hline Autoimmune disease & $4(1.0 \%)$ & 0 & $983(0.7 \%)$ & $0.590^{b}$ \\
\hline Liver cirrhosis & $1(0.2 \%)$ & 0 & $273(0.2 \%)$ & $0.890^{\mathrm{b}}$ \\
\hline Organ transplantation & $3(0.7 \%)$ & 0 & $122(0.1 \%)$ & $<0.001^{b}$ \\
\hline Acquired immuno-deficiency syndrome & 0 & 0 & $195(0.2 \%)$ & $0.691^{b}$ \\
\hline Arsenic intoxication & $1(0.2 \%)$ & 0 & $26(0.0 \%)$ & $0.006^{\mathrm{b}}$ \\
\hline \multicolumn{5}{|c|}{ No. of days in first 2 months of anti-tuberculosis treatment } \\
\hline $\begin{array}{l}\text { Receiving no anti-tuberculosis agents } \\
\text { Receiving } \geqslant 3 \text { anti-tuberculosis agents }\end{array}$ & $\begin{array}{c}3.7 \pm 7.0 \\
47.5 \pm 13.7\end{array}$ & $\begin{array}{c}3.0 \pm 6.0 \\
46.2 \pm 14.5\end{array}$ & $\begin{array}{c}3.5 \pm 7.0 \\
48.6 \pm 12.6\end{array}$ & $\begin{array}{l}0.672^{\mathrm{a}} \\
0.034^{\mathrm{a}}\end{array}$ \\
\hline Complete treatment with standard regimen & $284(69.1 \%)$ & $62(63.3 \%)$ & $96742(71.9 \%)$ & $0.078^{b}$ \\
\hline \multicolumn{5}{|c|}{$\begin{array}{l}\text { Abbreviation: COPD }=\text { chronic obstructive pulmonary disease. } \\
{ }^{a} \text { Calculated by independent-sample Student's } t \text {-test } \\
{ }^{b} \text { Calculated by } \chi^{2} \text {-square test. } \\
\text { Data were either number (\%) or mean } \pm \text { s.d. }\end{array}$} \\
\hline
\end{tabular}

Table 4. Cox regression analysis of factors possibly associated with the development of urothelial carcinoma among patients with tuberculosis

\begin{tabular}{|c|c|c|}
\hline & $\boldsymbol{P}$-value & $\begin{array}{c}\text { Hazard ratio } \\
(95 \% \text { confidence interval) }\end{array}$ \\
\hline Age (per year increment) & $<0.001$ & $1.05(1.04-1.06)$ \\
\hline Male & $<0.001$ & $1.55(1.22-1.98)$ \\
\hline End-stage renal disease & $<0.001$ & $7.16(4.81-10.63)$ \\
\hline Arsenic intoxication & 0.024 & $9.54(1.34-67.96)$ \\
\hline Urinary involvement of tuberculosis & $<0.001$ & $3.38(2.01-5.69)$ \\
\hline Obstructive uropathy & 0.024 & $1.31(1.04-1.66)$ \\
\hline Organ transplantation & 0.020 & $4.06(1.25-13.27)$ \\
\hline
\end{tabular}

of male and female patients separately, urinary TB remained an independent risk factor for developing urothelial carcinoma in both sexes, but the magnitude of association was higher among female patients than among male patients or the overall TB population (Table 6). For sub-population analyses of younger and older ( $\geqslant 60$ years) patients, UTB was also independently associated with the development of urothelial carcinoma in both age groups, but the hazards ratio of UTB was higher in younger patients.

\section{DISCUSSION}

Using a nationwide cohort, the present study clearly demonstrates that urinary $\mathrm{TB}$ involvement is an important risk factor for
Table 5. Cox regression analysis of factors possibly associated with the development of renal cell carcinoma among patients with tuberculosis

\begin{tabular}{|l|r|c|}
\hline & P-value & $\begin{array}{c}\text { Hazard ratio } \\
\text { (95\% confidence interval) }\end{array}$ \\
\hline Age (per year increment) & $<0.001$ & $1.02(1.01-1.04)$ \\
\hline Male & 0.008 & $2.05(1.21-3.48)$ \\
\hline End-stage renal disease & $<0.001$ & $6.57(2.85-15.14)$ \\
\hline Obstructive uropathy & 0.020 & $1.65(1.08-2.52)$ \\
\hline
\end{tabular}

Table 6. Sub-population analysis by sex and age groups for the impact of urinary tuberculosis on developing urothelial carcinoma

\begin{tabular}{|l|c|c|}
\hline Study population & P-value & $\begin{array}{c}\text { Hazard ratio } \\
\text { (95\% confidence interval) }\end{array}$ \\
\hline All & $<0.001$ & $3.38(2.01-5.69)$ \\
\hline Male & $<0.001$ & $2.96(1.57-5.60)$ \\
\hline Female & $<0.001$ & $5.26(2.12-13.06)$ \\
\hline Age $<60$ years & $<0.001$ & $6.41(2.56-16.09)$ \\
\hline Age $\geqslant 60$ years & 0.001 & $2.86(1.52-5.38)$ \\
\hline
\end{tabular}

developing urothelial carcinoma, especially among younger female patients. The strong association remains valid even after adjusting for other independent risk factors such as age, sex, ESRD, obstructive uropathy, history of organ transplantation, and arsenic intoxication. Nonetheless, regardless of whether TB involved the urinary tract had no significant impact on the risk of developing renal cell carcinoma. 
The urinary tract, especially the collecting system, is one of the most common sites of extra-pulmonary TB involvement (Wise and Marella, 2003). Unlike intra-vesical immunotherapy for urinary tract cancer with Bacillus Calmette-Guerin (BCG), which, after being internalised and processed by antigen-presenting cells and urothelial tumour cells, acts like killer cell targets to induce shortterm inflammation (Bevers et al, 2004; Mitropoulos, 2005), TB is characterised of chronic caseous granulomatous inflammation that can cause devastating tissue damage if left untreated (Elkington et al, 2011). Delay in TB diagnosis may vary from 3 to 6 months (Lawn et al, 1998; Steen and Mazonde, 1998; Lee et al, 2012). Diagnosing extra-pulmonary TB may even be more challenging. Delays in TB diagnosis and in the initiation of anti-TB treatment may increase the duration and severity of urinary tract inflammation and organ fibrosis, thus making the patient more vulnerable to urinary tract cancer. Furthermore, after the completion of anti-TB treatment, tissue scaring can still predispose to obstructive uropathy and subsequent urinary tract infection/inflammation (Ardalan and Shoja, 2008), which predispose to cell dysplasia and ongoing cancer formation (Kantor et al, 1984; Chow et al, 1997; Ling et al, 2011). During the chronic irritation phase, inflammatory cells like macrophages may also release some lymphangiopoietic vascular endothelial growth factors that may have a novel role in peri-tumoral lymphangiogenesis and subsequent dissemination of human cancer that predispose to dismal outcomes (Schoppmann et al, 2002).

Cox regression analyses restricted to those aged $<60$ and aged $\geqslant 60$ years separately demonstrated that UTB had a higher impact on the risk of urothelial carcinoma among younger patients. Sub-population analyses focused on each sex separately show that the risk for urinary tract cancer attributed to UTB is even higher among female patients. The baseline incidence of urothelial carcinoma was lower in the female patients compared with the male patients. The prevalence of smoking, a strong risk factor for urinary tract cancer, is also much lower among female patients than among male patients in Taiwan (Wen et al, 2005). Thus, UTB may act as the sole contributor to carcinogenesis among young female patients who are free of other risk factors for urothelial carcinoma. Furthermore, for patients with bladder cancer, female patients are associated with worse outcome than male patients, probably because female patients are more likely to have aggressive histology at initial presentation (Mungan et al, 2000; Jung et al, 2012; Noon et al, 2013). Thus, it is imperative that UTB patients, especially young female patients, be followedup carefully in the post-treatment period for subsequent urothelial carcinoma.

Cigarette smoking is the most important attributable risk for urothelial cancer and bladder cancer in Western countries (Johansson and Cohen, 1997), with over 60 known carcinogenic compounds in cigarette smoke (Hecht, 2006). In addition, cigarette smoking also increases the susceptibility to TB (Lin et al, 2009). Because smoking status is not available in the NHIRD, it is possible that some of the effects of UTB and male sex on the development of urothelial carcinoma observed in the present study were through the effects of cigarette smoking. However, in the sub-population analyses restricted to female and male patients separately, urinary TB remained an independent risk factor for urothelial carcinoma among the female patients, the predominantly non-smoking population (Wen et al, 2005), with a hazard ratio higher than that of male patients and the overall TB population. Hence, although the final Cox regression model in the present study was not adjusted for cigarette smoking, the effect of UTB on the risk of urothelial carcinoma should not be completely attributed to the confounding effect of cigarette smoking.

Except for UTB, risk factors of urothelial carcinoma disclosed in the present study, such as age, male sex, ESRD, obstructive uropathy, arsenic intoxication, and organ transplantation, are consistent with previous reports. In southern Taiwan, water with arsenic acid contamination is a known risk factor for several diseases, including urothelial carcinoma and blackfoot disease, a peripheral vascular disease (Tseng, 1989; Johansson and Cohen, 1997). Typically, urinary tract cancers are diagnosed in the elderly, predominantly those in the sixth to eighth decade, according to the National Cancer Institute's Surveillance (Howlader et al, 2013). Incidence increases with age and is two to three times higher in men than in women of the same age (Scosyrev et al, 2009; Siegel et al, 2011). In Taiwan, although the total incidence is not as high as that in western countries, the percentage of female patients is higher than in western countries, especially in the upper urinary tract malignancy group (Chou and Huang, 1999). However, the present study reveals that $80.2 \%$ of TB patients with urinary tract cancer are male. The ratio of male patients is much higher than that of the general population in Taiwan and even higher than that in western countries. As both age and male sex are risk factors for urinary tract cancer in TB patients, the exceptional male predominance in patients with urinary tract cancer in the present study is probably due to the male predominance and the advanced age of men than women among the enrolled TB patients.

In our results, organ transplantation was associated with a high risk of developing urothelial carcinoma. According to previous reports, de novo carcinoma in the transplantation recipients may be 10 times greater than in the general population (Viart et al, 2013). BK polyomavirus reactivation resulting from the use of immunosuppressant agents after transplantation is not uncommon. Such infections have been reported to cause aggressive urinary bladder urothelial carcinomas with adenocarcinomatous or micropapillary differentiation (Alexiev et al, 2013).

Patients with ESRD are reported to have a high incidence (520 per 100000 person-year) of developing renal cell carcinoma (Hurst et al, 2011) and higher mortality rate. Impaired function of antioxidant defence, relative immune-compromised status, and the accumulation of carcinogenic compounds due to renal dysfunction may result in increased prevalence and contribute to carcinogenesis (Vamvakas et al, 1997). For patients with ESRD, higher risks of cancers of the kidneys (3.60 (3.45-3.76)), bladder (1.50 (1.42-1.57)), and thyroid and other endocrine organs (2.28 (2.03-2.54)) have been observed (Maisonneuve et al, 1999). In the present study, part of the hazard of ESRD on urinary tract cancer may be attributed to the widespread use of Aristolochia herbal remedies in Taiwan. The Aristolochia acts as a common confounding factor for ESRD and urothelial carcinoma (Lai et al, 2010a, b). Thus, keeping a high suspicion of urinary tract cancer and performing ultrasonography of the kidneys and urinary tract, urine cytology, and endoscopy if indicated are important for ESRD patients, especially for those with a history of UTB.

The present study has some limitations. Mycobacterial findings are unavailable so uncertainty in the diagnosis of TB is inevitable. By applying a very strict definition for TB, the impact of UTB is likely to be underestimated because patients who have been excluded owing to poor adherence to anti-TB treatment are prone to more severe tissue scaring, ongoing chronic inflammation, and subsequent development of urinary tract cancer. Second, because the ICD-9-CM codes cannot differentiate among histologic types of urinary tract cancer (i.e., renal cell carcinoma, adenocarcinoma, and small cell carcinoma), the specific effects of UTB on individual histologic type of urinary tract cancer cannot be evaluated. Third, the interpretation of the causal relationship between UTB and urothelial carcinoma based on their temporality is difficult because there could be a delay in the diagnosis of either condition. Finally, the effects of socio-economic status and education level, which may confound both the occurrence of TB and urinary tract cancer development, cannot be reliably evaluated from the NHIRD. 


\section{CONCLUSIONS}

Urinary TB poses a high risk of developing urothelial carcinoma even after adjusting for other known risk factors such as age, sex, ESRD, obstructive uropathy, and arsenic intoxication. In TB endemic areas, the urinary tract of TB patients should be examined closely. Patients with urinary TB, especially for younger female patients, should be followed-up carefully in the post-treatment period. Ultrasonography of the kidneys and urinary tract, urine cytology, or endoscopy should also be an integral part of follow-up examinations. The distressing finding of subsequent urinary tract cancer dictates the need for early suspicion and intervention.

\section{ACKNOWLEDGEMENTS}

This study was supported by the National Science Council of Taiwan (grant NSC 99-2314-B-002-088-MY2) and the Research Center for Biotechnology and Medicine Policy (grant DOH-101DC-1101). The funders had no role in the study design, data collection, analysis and interpretation, decision to publish, or preparation of the manuscript.

\section{CONFLICT OF INTEREST}

All of the authors have completed the Unified Competing Interest form at www.icmje.org/coi_disclosure.pdf (available on request from the corresponding author) and declare that (1) no one has support from any company for the submitted work; (2) no one has any relationship with any company that may have an interest in the submitted work in the last the last years; (3) the authors' spouses, partners, or children have no financial relationships that may be relevant to the submitted work; and (4) no one has nonfinancial interests that may be relevant to the study.

\section{AUTHOR CONTRIBUTIONS}

Drs Yu-Chung Lien and Jann-Yuan Wang designed the study. Drs Yu-Chung Lien, Chih-Hsin Lee, Jann-Yuan Wang, Hsin-Yi Chen, Cheng-Hsing Hsieh, and Professor Kun-Mao Chao were all involved in the writing of the manuscript and in data interpretation. Ming-Chia Lee and Drs Chin-Chung Shu and Jann-Yuan Wang did the statistical analysis. Dr Chih-Hsin Lee and Professor Kun-Mao Chao developed the database queries and data modelling programs. Dr Chih-Hsin Lee is the guarantor for the manuscript.

\section{REFERENCES}

Alexiev BA, Randhawa P, Vazquez Martul E, Zeng G, Luo C, Ramos E, Drachenberg CB, Papadimitriou JC (2013) BK virus-associated urinary bladder carcinoma in transplant recipients: report of 2 cases, review of the literature, and proposed pathogenetic model. Hum Pathol 44(5): 908-917.

Ardalan MR, Shoja MM (2008) Radiological findings in renal tuberculosis: a report from northwest of Iran. Saudi J Kidney Dis Transplantat 19(1): 76-79.

Bevers RF, Kurth KH, Schamhart DH (2004) Role of urothelial cells in BCG immunotherapy for superficial bladder cancer. Br J Cancer 91(4): 607-612.

Blanc L, Falzon D, Fitzpatrick C, Floyd K, Garcia I, Gilpin C, Glaziou P, Hiatt T, Sculier D, Sismanidis C, Timimi H, Uplekar M (2010) Global Tuberculosis Control 2010. World Health Organization: Geneva, Switzerland.

Bureau of Health Promotion, Department of Health (2009) Cancer registry annual report: Cancer Control and Prevention Division. Bureau of Health Promotion, Department of Health: Taiwan, Republic of China.
Chang CH, Shau WY, Jiang YD, Li HY, Chang TJ, Sheu WH, Kwok CF, Ho LT, Chuang LM (2010a) Type 2 diabetes prevalence and incidence among adults in Taiwan during 1999-2004: a national health insurance data set study. Diabet Med 27(6): 636-643.

Chang FY, Shi WY, Lin T, Chou JH, Chen YH, Chuang JH, Yang CH, Yang SL, Lo HY, Lee CY, Wang KF, Chang PC (2010b) Taiwan Tuberculosis Control Report 2010. Centers for Disease Control, Department of Health, R.O.C (Taiwan): Taipei.

Chou YH, Huang CH (1999) Unusual clinical presentation of upper urothelial carcinoma in Taiwan. Cancer 85(6): 1342-1344.

Chow WH, Gridley G, Fraumeni Jr JF, Jarvholm B (2000) Obesity, hypertension, and the risk of kidney cancer in men. $N$ Engl J Med 343(18): 1305-1311.

Chow WH, Lindblad P, Gridley G, Nyren O, McLaughlin JK, Linet MS, Pennello GA, Adami HO, Fraumeni Jr JF (1997) Risk of urinary tract cancers following kidney or ureter stones. J Natl Cancer Inst 89(19): 1453-1457.

De Ridder D, van Poppel H, Demonty L, D’Hooghe B, Gonsette R, Carton H, Baert L (1998) Bladder cancer in patients with multiple sclerosis treated with cyclophosphamide. J Urol 159(6): 1881-1884.

Dou H-Y, Huang S-C, Su I-J (2011) Prevalence of mycobacterium tuberculosis in Taiwan: a model for strain evolution linked to population migration. Int J Evol Biol 2011: doi:10.4061/2011/937434.

Elkington P, Shiomi T, Breen R, Nuttall RK, Ugarte-Gil CA, Walker NF, Saraiva L, Pedersen B, Mauri F, Lipman M, Edwards DR, Robertson BD, D’Armiento J, Friedland JS (2011) MMP-1 drives immunopathology in human tuberculosis and transgenic mice. J Clin Investig 121(5): 1827-1833.

Hecht SS (2006) Cigarette smoking: cancer risks, carcinogens, and mechanisms. Langenbecks Arch Surg 391(6): 603-613.

Howlader NNA, Krapcho M, Garshell J, Neyman N, Altekruse SF, Kosary CL, Yu M, Ruhl J, Tatalovich Z, Cho H, Mariotto A, Lewis DR, Chen HS, Feuer EJ, Cronin KA (eds) (2013) SEER Cancer Statistics Review 1975-2010. National Cancer Institute: Besthesda, MD, USA.

Hurst FP, Jindal RM, Fletcher JJ, Dharnidharka V, Gorman G, Lechner B, Nee R, Agodoa LY, Abbott KC (2011) Incidence, predictors and associated outcomes of renal cell carcinoma in long-term dialysis patients. Urology 77(6): 1271-1276.

Johansson SL, Cohen SM (1997) Epidemiology and etiology of bladder cancer. Semin Surg Oncol 13(5): 291-298.

Jung KW, Park S, Shin A, Oh CM, Kong HJ, Jun JK, Won YJ (2012) Do female cancer patients display better survival rates compared with males? Analysis of the Korean National Registry data, 2005-2009. PLoS One 7(12): e52457.

Kakehi Y, Hirao Y, Kim WJ, Ozono S, Masumori N, Miyanaga N, Nasu Y, Yokomizo A (2010) Bladder Cancer Working Group report. Jpn J Clin Oncol 40(Suppl 1): i57-i64.

Kantor AF, Hartge P, Hoover RN, Narayana AS, Sullivan JW, Fraumeni Jr JF (1984) Urinary tract infection and risk of bladder cancer. Am J Epidemiol 119(4): 510-515.

Lai MN, Lai JN, Chen PC, Hsieh SC, Hu FC, Wang JD (2010a) Risks of kidney failure associated with consumption of herbal products containing $\mathrm{Mu}$ Tong or Fangchi: a population-based case-control study. Am J Kidney Dis 55(3): 507-518.

Lai MN, Wang SM, Chen PC, Chen YY, Wang JD (2010b) Population-based case-control study of Chinese herbal products containing aristolochic acid and urinary tract cancer risk. J Natl Cancer Inst 102(3): 179-186.

Lawn SD, Afful B, Acheampong JW (1998) Pulmonary tuberculosis: diagnostic delay in Ghanaian adults. Int J Tuberc Lung Dis 2(8): 635-640.

Lee CH, Lee MC, Lin HH, Shu CC, Wang JY, Lee LN, Chao KM (2012) Pulmonary tuberculosis and delay in anti-tuberculous treatment are important risk factors for chronic obstructive pulmonary disease. PLoS One 7(5): e37978.

Lee CH, Lee MC, Shu CC, Lim CS, Wang JY, Lee LN, Chao KM (2013) Risk factors for pulmonary tuberculosis in patients with chronic obstructive airway disease in Taiwan: a nationwide cohort study. BMC Infect Dis 13(1): 194.

Lin HH, Ezzati M, Chang HY, Murray M (2009) Association between tobacco smoking and active tuberculosis in Taiwan: prospective cohort study. Am J Respir Crit Care Med 180(5): 475-480.

Ling S, Chang X, Schultz L, Lee TK, Chaux A, Marchionni L, Netto GJ, Sidransky D, Berman DM (2011) An EGFR-ERK-SOX9 signaling cascade 
links urothelial development and regeneration to cancer. Cancer Res 71(11): 3812-3821.

Ljungberg B, Campbell SC, Choi HY, Jacqmin D, Lee JE, Weikert S, Kiemeney LA (2011) The epidemiology of renal cell carcinoma. Eur Urol 60(4): 615-621.

Luh K-T (ed.) (2011) Taiwan Guidelines for TB Diagnosis and Treatment. Centers for Disease Control, R.O.C. (Taiwan): Taipei, Taiwan.

Lynch CF, Cohen MB (1995) Urinary system. Cancer 75(Suppl 1): 316-329.

Maisonneuve P, Agodoa L, Gellert R, Stewart JH, Buccianti G, Lowenfels AB, Wolfe RA, Jones E, Disney AP, Briggs D, McCredie M, Boyle P (1999) Cancer in patients on dialysis for end-stage renal disease: an international collaborative study. Lancet 354(9173): 93-99.

Mamtani R, Haynes K, Bilker WB, Vaughn DJ, Strom BL, Glanz K, Lewis JD (2012) Association between longer therapy with thiazolidinediones and risk of bladder cancer: a cohort study. J Natl Cancer Inst 104(18): 1411-1421.

Mitropoulos DN (2005) Novel insights into the mechanism of action of intravesical immunomodulators. In Vivo 19(3): 611-621.

Mungan NA, Aben KK, Schoenberg MP, Visser O, Coebergh JW, Witjes JA, Kiemeney LA (2000) Gender differences in stage-adjusted bladder cancer survival. Urology 55(6): 876-880.

Noon AP, Albertsen PC, Thomas F, Rosario DJ, Catto JW (2013) Competing mortality in patients diagnosed with bladder cancer: evidence of undertreatment in the elderly and female patients. Br J Cancer 108(7): $1534-1540$.

Ploeg M, Aben KK, Kiemeney LA (2009) The present and future burden of urinary bladder cancer in the world. World J Urol 27(3): 289-293.

Pommer W, Bronder E, Klimpel A, Helmert U, Greiser E, Molzahn M (1999) Urothelial cancer at different tumour sites: role of smoking and habitual intake of analgesics and laxatives. Results of the Berlin Urothelial Cancer Study. Nephrol Dial Transplant 14(12): 2892-2897.

Public Assistance Act (2010) Taipei, Taiwan (R.O.C): Ministry of the Interior.
Schoppmann SF, Birner P, Stockl J, Kalt R, Ullrich R, Caucig C, Kriehuber E, Nagy K, Alitalo K, Kerjaschki D (2002) Tumor-associated macrophages express lymphatic endothelial growth factors and are related to peritumoral lymphangiogenesis. Am J Pathol 161(3): 947-956.

Scosyrev E, Noyes K, Feng C, Messing E (2009) Sex and racial differences in bladder cancer presentation and mortality in the US. Cancer 115(1): 68-74.

Siegel R, Ward E, Brawley O, Jemal A (2011) Cancer statistics, 2011: the impact of eliminating socioeconomic and racial disparities on premature cancer deaths. CA Cancer J Clin 61(4): 212-236.

Steen TW, Mazonde GN (1998) Pulmonary tuberculosis in Kweneng District, Botswana: delays in diagnosis in 212 smear-positive patients. Int $J$ Tuberc Lung Dis 2(8): 627-634.

Tseng WP (1989) Blackfoot disease in Taiwan: a 30-year follow-up study. Angiology 40(6): 547-558.

Vamvakas S, Bahner U, Heidland A (1997) Increased cancer incidence in terminal kidney failure: potential pathogenetic mechanisms. Schweiz Med Wochenschr 127(14): 597-604.

Viart L, Surga N, Collon S, Jaureguy M, Elalouf V, Tillou X (2013) The high rate of de novo graft carcinomas in renal transplant recipients. Am J Nephrol 37(2): 91-96.

Wen CP, Levy DT, Cheng TY, Hsu CC, Tsai SP (2005) Smoking behaviour in Taiwan, 2001. Tob Control 14(Suppl 1): i51-i55.

WHO International Working Group for Drug Statistics Methodology (2011) Guidelines for ATC classification and DDD assignment. WHO Collaborating Centre for Drug Statistics Methodology: Oslo, Norway.

Wise GJ, Marella VK (2003) Genitourinary manifestations of tuberculosis. Urol Clin North Am 30(1): 111-121.

(c) (1) (2) This work is licensed under the Creative Commons (c) ${ }_{\mathrm{BY}} \mathrm{NC}_{\mathrm{SA}}$ Attribution-NonCommercial-Share Alike 3.0 Unported License. To view a copy of this license, visit http://creativecommons. org/licenses/by-nc-sa/3.0/ 